\title{
Ageing and information: The Scottish older people's movement
}

\section{Bill Johnston}

\begin{abstract}
The author's role as the chair of the Scottish Senior's Alliance (SSA) provides insights into the need for Scotland to further develop information resources and services relevant to ageing and older people's needs, and to design systems to make that information accessible to: policy makers; service providers; media organisations; older people's organisations; and older people. The author's perspective is of an insider in the context of a notional 'older people's movement' committed to improving the circumstances, experiences and capacity of older people to sustain themselves and contribute to their communities. The author also has a long-standing academic interest in teaching, researching and advocating for Information Literacy.

Themes include discussed in the paper include trends in ageing populations, socio-economic changes and policy challenges, and the portrayal of older people in the media. Proposals include the development of Information Literacy (IL) in relation to older people, and aligning IL developments to a politically strategic approach to ageing and older people's interests in Scotland.
\end{abstract}

\section{Notes}

(i) For the purposes of this paper the UK Government's description of an 'older person' as anyone over 55 years is used.

(ii) For an official account of Scottish Constitutional History, a list of the main powers and responsibilities devolved to the Scottish Parliament with those reserved to Westminster, and an account of Scotland's Public Finances see Annexes A, B and C of Scotland's Future: Your Guide to an Independent Scotland (Scottish Government, 2013).

\section{Author}

Bill Johnston is Honorary Research Fellow in the School of Psychological Sciences and Health at Strathclyde University, and Chair of the Scottish Senior's Alliance (SSA).

Email: b.johnston@strath.ac.uk 


\section{Introduction: background and rationale}

The argument of this opinion paper is straightforward. As societies around the world experience demographic ageing, this creates larger numbers of people living longer within the population. Consequently there is an urgent need for nations and international organisations to reassess the implications for sustainable economic, social, health and educational policies. Information Literacy needs to become an integral part of this strategic process in terms of: research into older people's concepts and experiences of information; design and provision of relevant information services in respect of health, cost of living, pensions, lifelong learning, community engagement and many other areas of life; influencing state policies to incorporate an information literacy (IL) perspective as part of policy development for ageing populations.

A key focal issue is that of the agency and visibility of older people as informed advocates of their own interests and in combating negative images of ageing. In the words of Archbishop Desmond Tutu:

As we get older, our rights do not change. As we get older, we are no less human and should not become invisible.

(Global Age Watch Index, 2015).

Global Age Watch (2015) has projected total worldwide population, with the number and proportion of people aged $60+$ as follows:

2015: $901 \mathrm{M} ; 12.3 \%$

and then ...

2030: $1,402 \mathrm{M} ; 16.5 \%$

until ...

\section{0: $2,092 \mathrm{M} ; 21.5 \%$}

Whilst global population projections may vary there seems to be a consensus that populations around the world are ageing and that nations and international organisations must develop appropriate responses to support incomes, improve health and care services and generate the research to secure improvements in provision. It seems that older people will be more visible in the near future and there will be more of their voices to be heard.

The powerful political and economic forces associated with the consequences of ageing populations indicate that this raising of voices is essential. In the UK stagnant incomes since at least the 2008 economic crisis, alongside the Government guarantee on state on pension values, to 2020 at least, is creating a potential conflict between the generations (Collinson, 2016; Elliot, 2016).

Younger people are potentially losing sympathy for older generations and coming to see them as a privileged group who are living well off past prosperity, whilst the younger generation face poor wages, limited career opportunities, difficulty in securing mortgages, and all of the other conventional indicators of successful ageing post WW2. That this situation may have more to do with the economic policies of a sequence of post-war governments, and the problems of the global 
economy, than the supposed 'selfishness' of pensioners is an argument that needs to be made and widely debated.

However the intergenerational viability of public finances at a national level is an issue which must be addressed by policy makers and government officials. Lisenkova et al. (2015) offer an authoritative commentary on the problem using a model of intergenerational accounting, which illustrates the complexity and urgency of the matters involved. Consequently there is a need to combine state policy, economic options, media representation and informed public debate as a response to an ageing population. Where might the information come from?

\section{Information provision: A ‘one stop shop'?}

Arguably the better informed that governments and their citizens become, the greater the chance that demographic ageing will be well managed, and intergenerational conflicts, both fiscal and social, will be mitigated at least. The amount and variety of information generated around ageing is substantial, including, in this author's experience, sources such as: government departments; health services; local authorities; charities; researchers; media organisations; financial advisors; religious and community groups; trade unions; political parties; friends and families. Forms vary between: scientific papers on gerontology; government reports and position papers on public finance and service provision; self-help toolkits from charities; legal and money advice; public meetings; casual encounters in doctor's surgeries.

Headline grabbing stories in the news media about particular cases of hardship in old age are a regular contribution to the flow of information and shaping of perceptions. This 'human interest' content is complemented by more general feature stories about problems in care systems and their staffing, deterioration in state pension values and other politically charged issues. Political leaders typically are very positive about older people and their valuable contributions to society when asked their views. However there is the constant need for older people to evaluate how closely those words fit their experience of living standards, health care and financial security, combined with their perceptions of the degree of political attention paid to their interests.

This cornucopia offers a rich potential resource to support older people and others to understand ageing, advocate for improved public service systems, engage with private sector providers, design useful information products, and identify specific information about rights to services. Information should also help promote the efforts of older people and older people's organisations to have their voices heard in the busy world of politics, service provision, the media and the market. The range of relevant organisations concerned with ageing and older people's interests in Scotland is substantial and would warrant a separate paper to tease out their nature, purposes, relationships and information experiences. However for this paper the shorthand notion of a 'Scottish Older People's Movement' will have to suffice as a proxy for the valuable work of these organisations and also to give a sense of collective and collaborative agency amongst the older population.

The author's experience as chair of the Scottish Senior's Alliance, which seeks to raise public awareness of issues through an active role in lobbying politicians and 
working with other representative groups, highlights some key questions about information for ageing and the potential role of information literacy:

- What kinds of information are most relevant to older people?

- Which agencies originate and gather this information and how do they use it?

- How can older people gain increased understanding and control over information about themselves and their interests?

- How can state and commercial efforts to shift more information interactions online, for example welfare benefit claims, be controlled so as not to disadvantage older people?

- What support do older people need to get the best value from digital information services?

- How can negative media stereotypes be challenged?

In effect there is a very 'noisy' information system around ageing and older people, which is positive in providing an abundance of useful information in a variety of forms, but negative in its lack of a focus or common searching capacity. A way of focussing the place of information for older people is to suggest the need for a hypothetical 'one stop shop' to display all the relevant information wares and answer the points made above.

Such an emporium would not simply organise information and make it available but would also respond to some of the frustrations older people describe in the present situation. For example: government and other official materials experienced as being too complex to make sense of written by professionals for other professionals rather than older people; information rich institutions, such as health and care services, operating as professional fiefdoms with a tendency to overload user groups with highly technical information allied to organisational structures which appear to marginalise the voices of older users and their families. Allied to these concerns are the problems local seniors groups have in getting professional support from, say community workers, due to reductions in local authority staffing levels.

Similarly reductions in funding to libraries is seen as resulting in more limited services generally and to older users in particular given their very positive appreciation of the role of libraries in their lives. The recent (2016) Scottish Library and Information Council (SLIC) report on a national strategy for public libraries evidences this positive attitude in quotes from respondents. The overall theme of the report being that libraries are age friendly public spaces, which support local volunteering activities as well as serving individuals and communities.

However it will not be a surprise to discover that the notional 'one stop shop', attractive as it might be, has yet to be built.

\section{A role for information literacy?}

If a 'one stop shop' staffed by system designers, researchers and expert intermediaries is not available as yet, then it may be that older people and their 
representatives need to acquire IL to better exploit available information. This seems plausible in the light of the points made in the previous section and could be framed in terms of familiar 'sources, searching and evaluating' models of IL. Particularly so when professional intermediaries are on hand to help. Horton's paper for UNESCO (2007) is a good example of what might be considered against this model and his contribution is enhanced for our purposes by his focus on advocacy (2011), which seems to be a key aspect of developing IL in relation to public policy.

However it seems likely that some information-related research effort specific to older people would be useful. Wicks (2001) responds to the growing older population in Canada via a research study to address the issues arising from ageing, which complicate the information seeking of older people. Wicks notes the perceived tension between differing age groups in terms of technological sophistication and information seeking activities - the notion that 'younger' older people will be more comfortable than 'older' older people, for example. His interview based study illuminated aspects including: career histories; volunteering activities; computer use; library use; and sources of information used. Perhaps the most interesting insight lies in the listing of sources used: variety of media (mass print, TV, online); professionals such as pharmacists; volunteer community people and materials; Government publications; family and friends. This Canadian study discovered features of the older people's information environment very similar to those identified in Scotland by this author.

It is worth also considering other traditions in IL, which might usefully be applied. There is a strong strand of IL work which places value on exploring the experiences of users and their perceptions of information in their lifeworld. This strand has enriched understanding of IL and the development of improvements in given contexts. For example: Webber and Johnston (2000), Lloyd and Williamson (2008), and Bruce et al. (2014) identify the value of person orientated studies and the importance of context in understanding IL across a range of social groups. In this tradition IL is portrayed as a multidimensional, holistic phenomena, which is context sensitive and which changes and develops over the lifetime of individuals. This tradition also emphasizes the sociocultural nature of IL and its relevance to community based social activity.

Yates et al. (2009) explored the synergies between wellness and information in relation to ageing Australians, within the field of 'health information literacy'. Their approach employed a qualitative research methodology, phenomenography, and extended the scope of IL research beyond the familiar borders of higher education and workplace contexts. Their work discovered significant variation in concept and experience of health information literacy amongst the study participants and the six ways of experiencing health information literacy are worth reproducing here. The six categories uncovered as part of this research are as follows:

Category 1. Health information literacy is experienced as striving for wellness;

Category 2. Health information literacy is experienced as reaffirming wellness;

Category 3. Health information literacy is experienced as knowing myself; 
Category 4. Health information literacy is experienced as protecting myself;

Category 5. Health information literacy is experienced as screening knowledge;

Category 6. Health information literacy is experienced as storing knowledge.

The findings illustrate different ways of knowing about health and information and are significant in that they illuminate how professionally formulated concepts like 'health information literacy' are accessible to ordinary people in a community, and how such concepts are experienced in a particular age group. In terms of possible applications, the six categories have value in guiding the design of health information communications and managing interactions between different actors in health related environments, including relevant library and information services.

In summary, IL has much to offer all parties with an interest in ageing and the array of issues surrounding the lives of older people. How might this be progressed?

\section{A possible strategy: Integrating Government to manage an ageing population}

The outline response suggested here is in two parts; firstly a broad strategic direction for public policy on ageing and older people's issues in Scotland; secondly an estimate of the prospects for strategic change. These suggestions derive from the author's reflections over several years of involvement with older people's issues and advocacy, and are offered for debate and comparison to the situation in different national and international circumstances.

\subsection{A strategic approach to ageing populations}

- Develop public policy and practice for demographic ageing on a 25 year forward projection. This is essential given the projected growth in the ageing population and the need to avoid relying on short-term expedients driven by the five-year parliamentary cycle and immediate needs cast up by events;

- Audit and upgrade policy, practice and resourcing in provision of health, social care and other services for the current 70 plus age group - they need it now and improvements will benefit subsequent generations;

- Link the current 50 plus age group into the design of strategic responses for the future - they will need to become more aware of their future needs and contribute to creating a sustainable system which they will 'inherit' in the relatively near future;

- Develop whole of life educational strategies for improved citizenship, focusing in part on ageing, and align this with the development of future ageing policy, as well as engaging current participants at all levels of education with the experiences of current older generations. This would have a major intergenerational dynamic and should blend community experience with teaching, with both informed by the research on all aspects of ageing. Schools could develop a curriculum for citizenship emphasising intergenerational relationships and the details of public policy on ageing and 
age-related issues e.g. pensions as an aspect of personal finance and economics. Higher and further education could develop more age friendly offerings to local communities; researchers could create networks to identify and publicise age-related work across disciplines. Adult education with its wide range of age participation, offerings and practices would fit well in such a whole of life strategy.

Taken together these broad trajectories may go some way to achieving a holistic, coherent and sustainable approach to managing an ageing population. This in turn might give some guidance for the strategic development of the information provision and IL dimensions in relation to ageing.

\subsection{The Scottish political and social context and prospects for change}

There is no single focus for ageing and older people's issues at Ministerial level in the Scottish Government (save that the First Minister has final responsibility for all matters of Government). At present relevant responsibilities are spread across various ministerial portfolios in the Scottish Government. Also, in the devolved settlement of the Scottish Parliament the state pension is a UK responsibility reserved to Westminster. This creates a rather complex situation to understand and influence, which is further complicated by the current transfer of responsibility for certain social security benefits from Westminster to Holyrood.

Consequently clear lines of power, decision, accountability and associated information flows are difficult to discern. This militates against the deployment of focussed influence on the part of the older people's movement. It also contributes to the 'noisy' information environment discussed above, and will tend to impede the development of the coherence implied by the notion of a 'one stop shop'. At time of writing the Scottish Government is relatively unfocussed in relation to IL, tending to foreground the digital dimension of culture and social engagement, and appears to have relatively conventional views on libraries.

What is needed is a conceptual shift in public policy and a re-engineering of the mechanics of government to take advantage of the benefits of modern IL in the service of a more coherent approach to ageing. It may be that working with the concept of 'health information literacy' in relation to ageing would be a useful initial focus. A programme of action to draw together information resources on ageing and older people's issues more generally, and relate this knowledge base to the complex network of age related organisations, would also be an advance. This project would require the creation of age-friendly content and a mixed mode of access to the information. Equally there is a need to engage in critical analysis of media contributions and their impact on perceptions of ageing, which can influence public and political perceptions and decisions. The recent UNESCO/GAPMIL "Riga Recommendations" on media and information literacy (MIL) has a relevant statement calling on each UNESCO member State to "...promote awareness and recognition of the relevance of MIL to youth and ageing populations ...", which could be used to focus action (UNESCO, 2016).

Charities, local authorities, voluntary sector organisations, housing associations and other public institutions, which relate to ageing issues, tend to work in silos, and this militates against a holistic approach to ageing. In addition ageing is 
conventionally framed as an issue about 'older people' and assumed to be about welfare, health, pensions and other associated aspects deemed most relevant to the older age group. This tendency can be accentuated and distorted by media stereotypes of older people as 'weak', 'needy' and constantly requiring care. While this image has some substance in reality and requires a social response, it shows a darker side when it is translated into a political narrative of the growing costs to the taxpayer of supporting older people. This cost may then be characterised as becoming 'unsustainable' whilst being currently funded at the expense of struggling younger generations. What is needed are radical public, media and educational initiatives to shift the 'older people' framing into an 'ageing' frame as a start to a movement where social cohesion replaces potential intergenerational conflict as the objective of Scottish society.

This brief review does not present an overly optimistic prospect for change. However there are opportunities to be exploited. There is continuing emphasis on the question of Scottish Independence from the United Kingdom (UK) despite the decision in the 2014 Referendum against that option. Scotland remains part of the UK, however the Scottish National Party (SNP) remains in government at Holyrood, and has vastly increased its representation at Westminster following the 2015 UK General Election. The recent UK Referendum decision (June 2016) to leave the European Union (EU) is significant in that whilst the UK as a whole voted to leave, the Scottish electorate voted to remain in the EU. At time of writing it is difficult to assess where this difference in voting outcome might lead, but the question of Scottish Independence has obviously to be considered as an alternative scenario to remaining in a UK set on leaving the EU.

\section{Conclusion: Towards an age friendly, information literate Scotland}

Whatever happens over the next few years there will be substantial public debate on the nature and future of Scottish government, politics and society. How will a UK exit from the EU impact older people and future generations? Would an independent Scotland be a better alternative? What would an independent Scotland be like? How would it manage the ageing population and older people's issues? Would the introduction of a Minister for ageing and older people's issues be useful in any case? What are the implications for currently low visibility issues such as IL? How can consciousness of IL be raised across Scotland?

These questions should provide IL researchers and practitioners with much to debate and perhaps represent some focal issues for research and action. For older people themselves, there is a clear need to access information to counter negative stereotypes and to conduct campaigns to achieve improvements in service provision and counter any future attack on living standards.

\section{References}

Collinson, P. (2016) "We may have reached peak pensioner". The Guardian, 2 July 2016, 46.

Elliot, L. (2016) "Living until we are 100 will become a curse - unless we have health, jobs and equality". The Guardian, 25 April 2016, 22. 
Bruce, C. Davis, K. Hughes, H. Partridge, H. and Stoodley, I. (2014)Information Experience: Approaches to Theory and Practice. London, UK: Emerald.

Global Age Watch Index 2015 Insight report. URL: www.helpage.org/globalagewatch/reports/global-agewatch-index-2015-insight-report [accessed 17.05.2016]

Horton, F.W. (2007) Understanding Information literacy: A Primer, UNESCO Information for All Programme. Edited by the Information Society Division, Communications and Information Sector Paris: UNESCO, 2007.

Horton, F. W. (2011) Information Literacy Advocacy - Woody's Ten Commandments, Library Trends, 60(2), 262-276.

Lisenkova, K., Sanchez-Martinez, M. and Sefton, J. (2015) "The sustainability of Scottish public finances: a Generational Accounting approach". Discussion Paper No.456. London: National Institute of Economic and Social Research (NIESR):

Lloyd, A., and Williamson, K. (2008) Towards an understanding of information literacy in context: implications for research, Journal of Librarianship and Information Science, 40(1), 3-12.

Scottish Library and Information Council. (2015) Ambition \& Opportunity: A Strategy for Public Libraries in Scotland 2015-2020. Fife, UK: Scottish Library and Information Council.

Scottish Government (2013) Scotland's Future: Your Guide to an Independent Scotland, Edinburgh, Scotland: Scottish Government. URL http://www.gov.scot/resource/0043/00439021.pdf [accessed 01.06.2016]

UNESCO (2016) "Riga Recommendations on Media and Information Literacy in a Shifting Media and Information Landscape". URL http://www.unesco.org/new/fileadmin/MULTIMEDIA/HQ/CI/CI/pdf/Events/riga _recommendations_on_media_and_information_literacy.pdf [accessed 17.05.2016]

Webber, S. and Johnston, B. (2000) Conceptions of information literacy: new perspectives and implications, Journal of Information Science, 26(6), 381-397.

Wicks, Don A. (2001) "Go with the Flow": Independent Older Adults and Their Information Seeking", in Proceedings of the $27^{\text {th }}$ Annual Conference of CAIS/Actes du congrès annuel de l'ACSI. Canadian Association for Information Science, 149-164.

Yates, C., Partridge, H and Bruce, C. (2009) Learning wellness: how ageing Australians experience health information literacy, The Australian Library Journal, 58(3), 269-285. 


\section{Open access and copyright}

Library and Information Research is an open access journal. A freely available copy of this paper may be downloaded from the journal's website: http://www.lirgjournal.org.uk.

Copyright and associated moral rights in works published in Library and Information Research are retained by the author(s) but this paper may be used freely, with proper attribution, in educational and other non-commercial settings. 